\title{
Frequent epigenetic inactivation of Wnt antagonist genes in breast
}

\section{cancer}

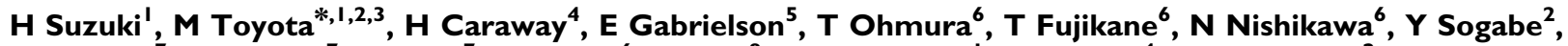 \\ M Nojima ${ }^{7}$, T Sonoda ${ }^{7}, M^{1}$ Mori $^{7}, K_{\text {Hirata }^{6}}, K_{\text {Imai }^{8}}$, Y Shinomura', SB Baylin ${ }^{4}$ and T Tokino ${ }^{2}$ \\ ${ }^{\prime}$ First Department of Internal Medicine, Sapporo Medical University, Sapporo, Japan; ${ }^{2}$ Department of Molecular Biology, Cancer Research Institute, \\ Sapporo Medical University, Sapporo, Japan; ${ }^{3}$ PRESTO, Japan Science and Technology Corporation, Kawaguchi, Japan; ${ }^{4}$ The Sidney Kimmel \\ Comprehensive Cancer Center at Johns Hopkins, Johns Hopkins University School of Medicine, Baltimore, MD, USA; ${ }^{5}$ Department of Pathology, Johns \\ Hopkins University School of Medicine, Baltimore, MD, USA; ${ }^{6}$ First Department of Surgery, Sapporo Medical University, Sapporo, Japan; ${ }^{7}$ Department of \\ Public Health, Sapporo Medical University, Sapporo, Japan; ' ${ }^{8}$ resident, Sapporo Medical University, Sapporo, Japan
}

\begin{abstract}
Although mutation of APC or CTNNBI ( $\beta$-catenin) is rare in breast cancer, activation of Wnt signalling is nonetheless thought to play an important role in breast tumorigenesis, and epigenetic silencing of Wnt antagonist genes, including the secreted frizzled-related protein (SFRP) and Dickkopf (DKK) families, has been observed in various tumours. In breast cancer, frequent methylation and silencing of SFRP I was recently documented; however, altered expression of other Wnt antagonist genes is largely unknown. In the present study, we found frequent methylation of SFRP family genes in breast cancer cell lines (SFRPI, 7 out of I I, 64\%; SFRP2, I I out of II, I00\%; SFRP5, 10 out of II, 91\%) and primary breast tumours (SFRPI, 31 out of 78, 40\%; SFRP2, 60 out of 78, 77\%; SFRP5, 55 out of $78,71 \%$ ). We also observed methylation of DKKI, although less frequently, in cell lines (3 out of II, 27\%) and primary tumours (I 5 out of 78, 19\%). Breast cancer cell lines express various Wnt ligands, and overexpression of SFRPs inhibited cancer cell growth. In addition, overexpression of a $\beta$-catenin mutant and depletion of SFRPI using small interfering RNA synergistically upregulated transcriptional activity of T-cell factor/lymphocyte enhancer factor. Our results confirm the frequent methylation and silencing of Wnt antagonist genes in breast cancer, and suggest that their loss of function contributes to activation of Wnt signalling in breast carcinogenesis.

British Journal of Cancer (2008) 98, | |47- | | 56. doi: I0. I038/sj.bjc.6604259 www.bjcancer.com

Published online 19 February 2008

(c) 2008 Cancer Research UK
\end{abstract}

Keywords: Wnt; SFRP; DKKI; methylation; breast cancer

Wnt ligands are secreted proteins that bind to transmembrane receptors in the Frizzled (Fz) family. During normal developmental processes, the resultant Wnt signalling plays essential roles in the regulation of cell proliferation, patterning and fate determination (Cadigan and Nusse, 1997). The binding of Wnt to $\mathrm{Fz}$ leads to dephosphorylation and stabilisation of $\beta$-catenin, enabling it to be translocated into the nucleus, where it interacts with members of the T-cell factor/lymphocyte enhancer factor (TCF/LEF) family of transcription factors to stimulate the expression of target genes. This signalling pathway is strongly implicated in tumorigenesis; indeed, the first mammalian Wnt isoform was identified based on its ability to promote mouse mammary tumorigenesis (Polakis, 2000). In addition, aberrant nuclear and cytoplasmic localisation of $\beta$-catenin is frequently observed in human breast cancer (Lin et al, 2000; Ryo et al, 2001; Chung et al, 2004). In contrast to colorectal cancer (CRC), however, mutation of $A P C, A X I N$ or CTNNB1 ( $\beta$-catenin) is rare in

*Correspondence: Dr M Toyota, First Department of Internal Medicine, Sapporo Medical University, SI, WI6, Chuo-Ku, Sapporo 060-8543, Japan; E-mail: mtoyota@sapmed.ac.jp

Received 30 August 2007; revised 14 January 2008; accepted 18 January 2008; published online 19 February 2008 breast cancer, indicating that other mechanisms are responsible for the activation of $\beta$-catenin. These mechanisms could include increased expression of Wnt ligand (Huguet et al, 1994; Dale et al, 1996; Bui et al, 1997) and/or the loss of Wnt antagonists.

Several classes of secreted Wnt antagonists are known, including the Cerberus, Wnt inhibitory factor 1, secreted frizzled-related protein (SFRP) and the Dickkopf (DKK) families (Kawano and Kypta, 2003). The SFRP family is comprised of five secreted glycoproteins identified as putative inhibitors of the Wnt signalling pathway (Jones and Jomary, 2002). Secreted frizzled-related proteins contain an $\mathrm{N}$-terminal domain homologous to the cysteine-rich domain (CRD) of $\mathrm{Fz}$ and a C-terminal domain with some homology to netrin. This enables SFRPs to downregulate Wnt signalling by competing with $\mathrm{Fz}$ for Wnt binding via its CRD domain or by binding directly to Fz (Jones and Jomary, 2002). Vertebrates express four DKK proteins and a unique DKK3-related protein called Soggy (Niehrs, 2006). Dickkopf-1 binds to lowdensity lipoprotein receptor-related protein 5/6 (LRP5/6) and another transmembrane protein, Kremen, to selectively inhibit the canonical Wnt pathway by preventing Wnt and Fz from forming a ternary complex with LRP5/6 (Niehrs, 2006).

Epigenetic silencing of tumour suppressor and tumour-related genes in association with promoter $\mathrm{CpG}$ island hypermethylation 
is a frequent event that has been seen in virtually every tumour type (Ting et al, 2006). When we screened for epigenetically silenced genes in CRC, we found that multiple members of the $S F R P$ family are concurrently methylated at high frequencies among cultured CRC cells and primary CRC specimens (Suzuki et al, 2002). We also found evidence that loss of SFRP function contributes to the activation of Wnt signalling in CRC cells (Suzuki et al, 2004). That SFRP1 is located in a chromosomal region that is frequently deleted in breast cancer $(8 \mathrm{p} 12-\mathrm{p} 11.1)$ suggests that SFRP1 may also play a tumour suppressor role during mammary tumorigenesis (Ugolini et al, 1999, 2001; Armes et al, 2004). Consistent with that idea, we have previously found that SFRP1 is methylated in several breast cancer cell lines (Suzuki et al, 2002), and two other groups recently reported frequent SFRP1 methylation in both primary and cultured breast cancer cells (Lo et al, 2006; Veeck et al, 2006). To date, epigenetic silencing of SFRP1 has been identified in a variety of malignancies, including cancers of the bladder (Stoehr et al, 2004), prostate (Lodygin et al, 2005), lung (Fukui et al, 2005) and breast, although abnormalities involving other SFRP family genes are largely unexplored.

We previously showed that SFRP1, SFRP2 and SFRP5 are frequently inactivated in CRC and gastric cancer (GC) (Suzuki et al, 2002; Nojima et al, 2007), and that SFRPs suppress constitutive Wnt signalling when overexpressed in CRC and GC cells. Similarly, Bafico et al (2004) reported that constitutive Wnt signalling could be suppressed in breast cancer cells by SFRP1 and DKK1. DKK1 also has been shown to be a target of methylationassociated silencing in CRC cells (Aguilera et al, 2006). In the present study, we attempted to characterise the epigenetic abnormalities of Wnt antagonist genes in breast cancer and to determine whether SFRP genes function as tumour suppressors in the breast.

\section{MATERIALS AND METHODS}

\section{Cell lines and tissue specimens}

Six breast cancer cell lines (MDA-MB-231, MDA-MB-435S, MDAMB-436, MDA-MB-468, MDA-MB-157, MDA-MB-453) were purchased from the American Type Culture Collection (Manassas, VA, USA), and five (MCF-7, T-47D, SK-BR-3, MDA-MB-361 and ZR75-1) were purchased from Dainippon Sumitomo Pharma (Osaka, Japan). The two CRC cell lines (RKO and DKO2) used were described previously (Toyota et al, 2003). All of the cell lines were cultured in the appropriate medium. To analyse restoration of $S F R P$ gene expression, cells were treated with $2 \mu \mathrm{M} 5$-aza- $2^{\prime}-$ deoxycytidine (DAC) (Sigma, St Louis, MO, USA) for $72 \mathrm{~h}$, replacing the drug and medium every $24 \mathrm{~h}$. A total of 38 breast tumour specimens were obtained from Department of Pathology at Johns Hopkins Medicine (Baltimore, MD, USA). In addition, 78 primary breast tumour specimens from 78 Japanese patients were obtained from the First Department of Surgery, Sapporo Medical University. Informed consent was obtained from all patients before collection of the specimens. Genomic DNA was extracted using the standard phenol-chloroform procedure. Total RNA was extracted by using Trizol reagent (Invitrogen, Carlsbad, CA, USA) and then treated with a DNA-free kit (Ambion, Austin, TX, USA). Total RNA from normal breast tissue from a healthy individual was purchased from BioChain (Hayward, CA, USA).

\section{Reverse transcriptase-PCR}

Single-stranded cDNA was prepared using SuperScript III reverse transcriptase (RT) (Invitrogen). The integrity of the cDNA was confirmed by amplifying glyceraldehyde-3-phosphate dehydrogenase $(G A P D H)$. PCR was run in a $50-\mu$ l volume containing $100 \mathrm{ng}$ of cDNA, $1 \times$ Ex Taq Buffer (TaKaRa, Otsu, Japan), $0.3 \mathrm{~mm}$
dNTP, $0.25 \mu \mathrm{M}$ each primer and $1 \mathrm{U}$ of TaKaRa Ex Taq Hot Start Version (TaKaRa). The PCR protocol entailed $5 \mathrm{~min}$ at $95^{\circ} \mathrm{C} ; 35$ cycles of $1 \mathrm{~min}$ at $95^{\circ} \mathrm{C}, 1 \mathrm{~min}$ at $55^{\circ} \mathrm{C}$ and $1 \mathrm{~min}$ at $72^{\circ} \mathrm{C}$; and a 7 min final extension at $72^{\circ} \mathrm{C}$. Primer sequences for RT-PCR analysis are listed in Table 1. Real-time RT-PCR was carried out using SYBR Green sequence detection reagents (Applied Biosystems, Foster City, CA, USA) in a $50-\mu \mathrm{l}$ volume containing $100 \mathrm{ng}$ of cDNA, $25 \mu \mathrm{l}$ of SYBR Green PCR Master Mix (Applied Biosystems) and $0.2 \mu \mathrm{m}$ each primer. The PCR protocol entailed $5 \mathrm{~min}$ at $95^{\circ} \mathrm{C}$ and 40 cycles of $30 \mathrm{~s}$ at $95^{\circ} \mathrm{C}$ and $1 \mathrm{~min}$ at $60^{\circ} \mathrm{C}$. Fluorescent signals were detected using an ABI 7000 Prism 7000 (Applied Biosystems), and the accumulation of PCR product was measured in real time as the increase in SYBR green fluorescence. Data were analysed using ABI Prism 7000 SDS Software (Applied Biosystems). Standard curves relating initial template copy number to fluorescence and amplification cycle were generated using the amplified PCR product as a template, and were used to calculate mRNA copy number in each sample. Ratios of the intensities of the target genes and GAPDH signals were used as a relative measure of the expression level of target genes. Primer sequences for real-time RT-PCR are listed in Table 1.

\section{Methylation analysis}

Bisulphite treatment of genomic DNA was performed as described previously (Suzuki et al, 2002). Methylation was then analysed using methylation-specific PCR (MSP) and bisulphite sequencing. PCR was run in a $25-\mu$ l volume containing $50 \mathrm{ng}$ bisulphite-treated DNA, $1 \times \quad$ MSP buffer $(67 \mathrm{~mm}$ Tris- $\mathrm{HCl} \quad(\mathrm{pH} \quad 8.8), 16.6 \mathrm{~mm}$ $\left(\mathrm{NH}_{4}\right)_{2} \mathrm{SO}_{4}, \quad 6.7 \mathrm{mM} \quad \mathrm{MgCl}_{2}$ and $10 \mathrm{~mm}$ 2-mercaptoethanol), $1.25 \mathrm{~mm}$ dNTP, $0.4 \mu \mathrm{M}$ each primer and $0.5 \mathrm{U}$ of JumpStart REDTaq DNA Polymerase (Sigma). The PCR protocol for MSP entailed $5 \mathrm{~min}$ at $95^{\circ} \mathrm{C} ; 35$ cycles of $30 \mathrm{~s}$ at $95^{\circ} \mathrm{C}, 30 \mathrm{~s}$ at $60^{\circ} \mathrm{C}$ and $30 \mathrm{~s}$ at $72^{\circ} \mathrm{C}$; and a 7 -min final extension at $72^{\circ} \mathrm{C}$. The PCR protocol for bisulphite sequencing entailed $5 \mathrm{~min}$ at $95^{\circ} \mathrm{C} ; 35$ cycles of $1 \mathrm{~min}$ at $95^{\circ} \mathrm{C}, 1 \mathrm{~min}$ at $60^{\circ} \mathrm{C}$ and $1 \mathrm{~min}$ at $72^{\circ} \mathrm{C}$; and a 7 -min final extension at $72^{\circ} \mathrm{C}$. Amplified bisulphite-sequencing PCR products were cloned into pCR2.1-TOPO vector (Invitrogen), and 10 clones from each sample were sequenced. Primer sequences are listed in Table 1.

\section{Immunofluorescence microscopy}

Cells cultured on chamber slides were washed with PBS and fixed in $4 \%$ paraformaldehyde, after which they were incubated with anti- $\beta$-catenin monoclonal antibody (BD Transduction Laboratories, San Diego, CA, USA) and stained with anti-mouse IgG conjugated with Alexa Fluor 488 (Invitrogen). Cells were then examined using an FV300-IX71 confocal laser scanning microscope (Olympus, Tokyo, Japan).

\section{Colony formation assays}

Cells $\left(2 \times 10^{6}\right.$ cells $)$ were transfected with $5 \mu \mathrm{g}$ of one of the pcDNA3.1/His-SFRP vectors or with empty vector using the Cell Line Nucleofector kit V (Amaxa, Cologne, Germany) and a Nucleofector I electroporation device (Amaxa), according to the manufacture's instructions. The SFRP vectors were prepared as described previously (Suzuki et al, 2004), and an empty vector, pcDNA3.1/HisA (Invitrogen), was used as a control. Cells were plated on $60-\mathrm{mm}$ culture dishes and selected for 14 days with $0.6 \mathrm{mg} \mathrm{ml}^{-1} \mathrm{G} 418$, after which colonies were stained with Giemsa and counted using National Institute of Health IMAGE software.

\section{Flow cytometry}

Fluorescence-activated cell sorting (FACS) analysis was carried out as described previously (Nojima et al, 2007). Briefly, $2 \times 10^{6}$ cells 
Table I Sequences for primers and siRNA used in this study

\begin{tabular}{|c|c|c|c|}
\hline Gene name & Sense & Antisense & Product size (bp) \\
\hline \multicolumn{4}{|l|}{ RT-PCR } \\
\hline SFRPI & 5'-CCAGCGAGTACGACTACGTGAGCTT-3' & 5'-CTCAGATTTCAACTCGTTGTCACAGG-3' & 497 \\
\hline$D K K I$ & 5'-CTTTCTCCCTCTTGAGTCCTTCTG-3' & 5'-CATAGCGTGACGCATGCAGCGTT-3' & 404 \\
\hline Wntl & 5'-GTCTGATACGCCAAAATCCGG-3' & 5'-CTCGTTGTTGTGAAGGTTCATG-3' & 404 \\
\hline Wnt2 & 5'-TTGAAACAAGAGTGCAAGTGCC-3' & 5'-ACTTACACCCACACTTGGTCAT-3' & 379 \\
\hline Wnt3A & 5'-GGCATCAAGATTGGCATCCAG-3' & 5'-CACTTGAGGTGCATGTGGCTG-3' & 404 \\
\hline Wnt4 & 5'-ATGCTCTGACAACATCGCCTA-3' & 5'-TGCGGCTTGAACTGTGCGTTG-3' & 333 \\
\hline Wnt5A & 5'-TGGAAGTGCAATGTCTTCCAAG-3' & 5'-AGGTGTTATCCACAGTGCTGCA-3' & 314 \\
\hline Wnt5B & 5'-GAAGCTGTGCCAATTGTACCA-3' & 5'-ATCCACAAACTCCTTGGCGAA-3' & 355 \\
\hline Wnt7A & 5'-GCAAGCATCATCTGTAACAAGA-3' & 5'-TCTCTTTGTCGCAGCCACAGT-3' & 310 \\
\hline Wnt7B & 5'-CATCAACGAGTGCCAGTACCA-3' & 5'-CCTCATTGTTATGCAGGTTCAT-3' & 353 \\
\hline Wntll & 5'-GAACTGCTCCTCCATTGAGCT-3' & 5'-CTTACACTTCATTTCCAGAGAG-3' & 364 \\
\hline \multicolumn{4}{|l|}{ Real time RT-PCR } \\
\hline SFRPI & 5'-AGATGCTTAAGTGTGACAAGTTCC-3' & 5'-TCAGATTTCAACTCGTTGTCACAG-3' & 130 \\
\hline AXIN2 & 5'-TCAAGTGCAAACTTTCGCCAACC- $3^{\prime}$ & 5'-TAGCCAGAACCTATGTGATAAGG-3' & $|5|$ \\
\hline MMP7 & 5'-TCACTTCGATGAGGATGAACGC-3' & 5'-ATCACTGCATTAGGATCAGAGGA-3' & 126 \\
\hline GAPDH & 5'-CTCTGGTAAAGTGGATATTGTTGC-3' & 5'-CCTTGACGGTGCCATGGAATTTG-3' & 113 \\
\hline \multicolumn{4}{|c|}{ Methylation analysis } \\
\hline SFRPI MSP-U & 5'-GTITGTAGTITTGGAGTTAGTGTTGTGT-3' & $5^{\prime}-$-CTCAACCTACAATCAAAAACAACACAAACA-3' & 135 \\
\hline SFRPI MSP-M & 5'-TGTAGTITTCGGAGTTAGTGTCGCGC-3' & $5^{\prime}$-CCTACGATCGAAAACGACGCGAACG-3' & 126 \\
\hline SFRP2 MSP-U & 5'-TाTGGGTTGGAGTTाTTGGAGTTGTGT-3' & 5'-AACССАСТСТСТTСАСТАAATACAACTCA-3' & 145 \\
\hline SFRP2 MSP-M & 5'-GGGTCGGAGTTTTCGGAGTTGCGC-3' & 5'-CCGCTCTCTTCGCTAAATACGACTCG-3' & 138 \\
\hline SFRP5 MSP-U & 5'-GTAAGATTTGGTGTTGGGTGGGATGTTT-3' & 5'-AAAACTCCAACCCAAACCTCACCATACA-3' & 136 \\
\hline SFRP5 MSP-M & 5'-AAGATTTGGCGTTGGGCGGGACGTTC-3' & 5'-ACTCCAACCCGAACCTCGCCGTACG-3' & $|4|$ \\
\hline DKKI MSP-U & 5'-TTAAGGGGTTGGAATGTTITGGGTITGT-3' & 5'-AAACCTAAATCCCCACAAAACCATACCA-3' & 163 \\
\hline DKKI MSP-M & 5'-AGGGGTCGGAATGTTTCGGGTTCGC-3' & $5^{\prime}$-CCTAAATCCCCACGAAACCGTACCG-3' & 157 \\
\hline
\end{tabular}

$\mathrm{MSP}=$ methylation-specific PCR; RT = reverse transcriptase; siRNA = small interfering RNA.

were transfected with one of the SFRP vectors or with an empty vector as described above. Forty-eight hours after transfection, the cells were harvested, fixed with methanol, rehydrated with PBS, treated with $2 \mu \mathrm{g} \mathrm{ml}^{-1}$ RNase for $30 \mathrm{~min}$ at $37^{\circ} \mathrm{C}$, stained in propidium iodide solution $\left(50 \mu \mathrm{g} \mathrm{ml}^{-1}\right)$ and analysed using a FACSCalibur instrument (Becton Dickinson, San Jose, CA, USA).

\section{Small interfering RNA-mediated knockdown of SFRP1}

For small interfering RNA (siRNA)-mediated knockdown of SFRP1, three different oligonucleotide dsRNAs against SFRP1 (siSFRP1) were generated by Dharmacon (Lafayette, CO, USA), after which a mixture of the three was used for transfection. The sequences of the siRNA oligonucleotides are listed in Table 1. A negative control siRNA, siCONTROL, was also purchased from Dharmacon. Cells $\left(2 \times 10^{6}\right.$ cells $)$ were transfected with $1.5 \mu \mathrm{g}$ of siSFRP1 or siCONTROL using the Cell Line Nucleofector kit V (Amaxa) and a Nucleofector I electroporation device (Amaxa), according to the manufacturer's instructions. Total RNA was extracted $48 \mathrm{~h}$ after transfection, and SFRP1 expression was analysed by RT-PCR.

\section{Cell viability assay}

Proliferation of siRNA transfectants was analysed by measuring the uptake of tritium thymidine in 3-(4,5-dimethylthiazol-2-yl)2,5-diphenyltetrazolium bromide (MTT) assays. Transfected cells were seeded into 96 -well plates to a density of $5 \times 10^{3}$ cells per well. After incubation for $48 \mathrm{~h}$, MTT assays were carried out using a Cell Counting kit-8 (Dojindo, Tokyo, Japan), according to the manufacturer's instructions. The colorimetric read-out in this assay reflects the number of metabolically active mitochondria, and thus viable cells, in a given well.

\section{Analysis of TCF/LEF-mediated transcription}

An expression vector encoding a mutant form of $\beta$-catenin, pcDNA3.1- $\beta$-catenin $\Delta 45$, was prepared as described previously (Suzuki et al, 2004). For the combination analysis of mutant $\beta$-catenin and siSFRP1, MDA-MB-436 cells were cotransfected with $5 \mu \mathrm{g}$ of pcDNA3.1- $\beta$-catenin $\Delta 45$ or empty vector plus $1.5 \mu \mathrm{g}$ of siSFRP1 or siCONTROL using the Cell Line Nucleofector kit V (Amaxa). RNA was prepared $48 \mathrm{~h}$ after transfection, and RT-PCR was performed as described above. For TCF/LEF-responsive 
reporter assays, MDA-MB-436 cells were transfected with $100 \mathrm{ng}$ of pGL3-OT (a TCF/LEF-responsive luciferase reporter plasmid) or pGL3-OF (a negative control plasmid), $100 \mathrm{ng}$ of pcDNA3.1$\beta$-catenin $\Delta 45$ or empty vector, $1 \mathrm{ng}$ of $\mathrm{pRL}-\mathrm{CMV}$ and $100 \mathrm{nM}$ of siSFRP1 or siCONTROL using Lipofectamine 2000 (Invitrogen). Firefly and Renilla luciferase activities were measured $48 \mathrm{~h}$ after transfection using a Dual-Luciferase Reporter Assay System (Promega, Madison, WI, USA) and a Lumat LB 9507 luminometer (Berthold Technologies, Bad Wildbad, Germany).

\section{Statistical analysis}

Statistical analyses were carried out using SPSS software (version 11.0; SPSS Inc., Chicago, IL, USA). Mann-Whitney's U-test and Fisher's exact test (two-sided) were used to evaluate the association between methylation of Wnt antagonist genes and clinicopathological features. Values of $P<0.05$ were considered significant.

\section{RESULTS}

\section{Analysis of Wnt antagonist gene expression in breast cancer cell lines}

We previously reported that three of the five SFRP genes (SFRP1, SFRP2 and SFRP5) were frequently methylated and silenced in CRC and GC cells (Suzuki et al, 2002; Nojima et al, 2007). For that reason, in the present study we initially evaluated the expression status of SFRP1, SFRP2 and SFRP5 in a panel of breast cancer cell lines. We found that SFRP1 mRNA was completely absent in 4 of the 11 cell lines tested (MCF-7, MDA-MB-231, T-47D and
SK-BR-3) and was downregulated in one cell line (MDA-MB-453) (Figure 1A). Treating the cells with the DNA methyltransferase (DNMT) inhibitor DAC rapidly restored its expression (Figure 1A).

SFRP2 expression was absent in eight cell lines (MCF-7, MDAMB-231, MDA-MB-435S, MDA-MB-468, T-47D, SK-BR-3, MDAMB-453 and ZR-75-1) and downregulated in two (MDA-MB-436 and MDA-MB-361) (Figure 1A), while SFRP5 expression was absent in nine cell lines (MCF-7, MDA-MB-231, MDA-MB-436, T-47D, SK-BR-3, MDA-MB-157, MDA-MB-361, MDA-MB-453 and ZR-75-1) and downregulated in two (MDA-MB-435S and MDAMB-468) (Figure 1A). 5-Aza-2'-deoxycytidine treatment restored mRNA expression in the majority of the cells in which SFRP2 and/ or SFRP5 were downregulated (Figure 1A).

As $D K K 1$ was recently shown to be epigenetically silenced in CRC, we also analysed expression of $D K K 1$ in the breast cancer cells. We found that DKK1 mRNA was significantly downregulated in two cell lines (T-47D and MDA-MB-453), and the expression was restored by DAC treatment (Figure 1A). In contrast to cancer cells, all Wnt antagonist genes were expressed in normal breast tissue (Figure 1A).

\section{Analysis of Wnt antagonist gene methylation in breast cancer cell lines}

We next used MSP to analyse the methylation status of Wnt antagonist genes. A CRC cell line (RKO) in which all of the Wnt antagonist genes were methylated served as a positive control, while another CRC cell line (DKO2) in which the DNMT1 and $D N M T 3 B$ loci were genetically disrupted served as a negative

A

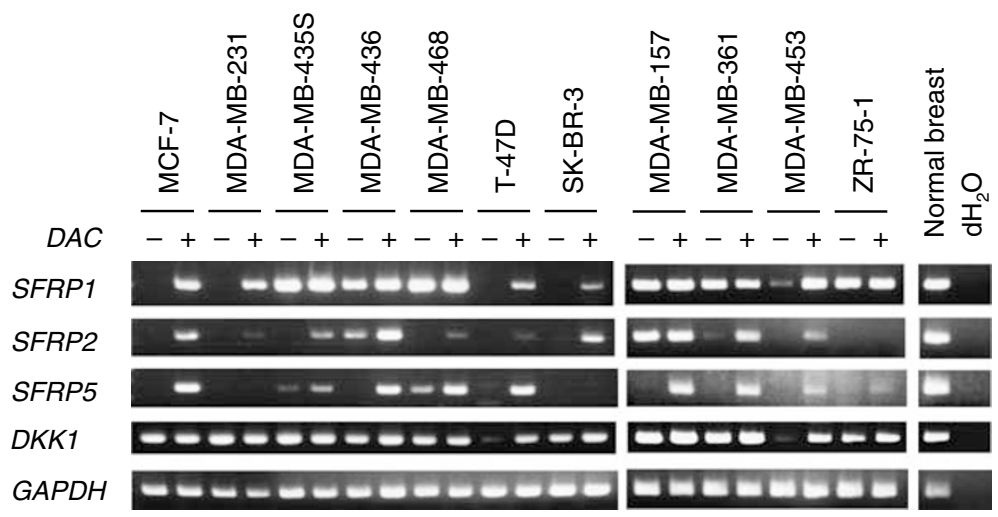

B

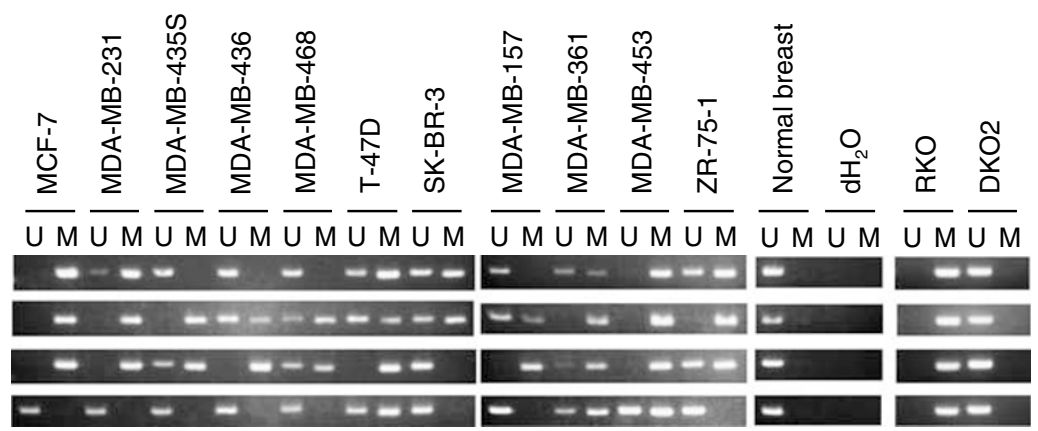

Figure I Analysis of the expression and methylation of Wnt antagonist genes in breast cancer cell lines. (A) RT-PCR analysis of SFRPI, SFRP2, SFRP5 and DKKI expression in the indicated breast cancer cell lines, with and without DAC treatment, and in a normal breast tissue. Expression of GAPDH was assessed in all samples to ensure the cDNA quality; $\mathrm{dH}_{2} \mathrm{O}$ indicates no RNA added. (B) MSP analysis of the indicated breast cancer cell lines and normal breast tissue. A methylated CRC cell line (RKO) and another CRC cell line in which DNMTI and DNMT3B were genetically disrupted (double knockout; DKO2), respectively, served as positive and negative controls of methylation. Bands in the ' $M$ ' lanes are PCR products obtained with methylation-specific primers; those in the ' $\mathrm{U}$ ' lanes are products obtained with unmethylated-specific primers; $\mathrm{dH}_{2} \mathrm{O}$ indicates no DNA added. 
control (Figure 1B). We observed SFRP1 methylation in 7 of the $11(64 \%)$ breast cancer cell lines tested (MCF-7, MDA-MB-231, T-47D, SK-BR-3, MDA-MB-361, MDA-MB-453 and ZR-75-1) (Figure 1B). Of those, expression of SFRP1 mRNA was downregulated in five, as described above. We also detected SFRP1 methylation in two cell lines in which basal expression of the gene remained intact (MDA-MB-361 and ZR-75-1) (Figure 1A and B). As both methylated and unmethylated SFRP1 was detected in these cells, we suggest that the mRNA was likely transcribed from the unmethylated allele.

SFRP2 methylation was detected in all 11 cell lines (100\%), while SFRP5 methylation was detected in 10 (91\%) (Figure 1B). In general, we observed a good correlation between methylation and the expression status of SFRP2 and SFRP5, although there were some exceptions. For example, some methylation of SFRP2 was detected in MDA-MB-157 cells (Figure 1B), but they showed a substantial amount of basal mRNA expression (Figure 1A), which was likely transcribed from the unmethylated allele. Conversely, SK-BR-3 cells showed no SFRP5 methylation but did not express any mRNA. Since DAC treatment did not restore SFRP5 expression in SK-BR-3 cells, a different mechanism may be responsible for its silencing.
Methylation of DKK1 was detected in three cell lines (T-47D, MDA-MB-361 and MDA-MB-453) (Figure 1B), although none of the cells showed complete methylation of $D K K 1$, and MSP revealed both methylated and unmethylated DNA (Figure 1B). These results are consistent with the observation that two cell lines showed significant downregulation of $D K K 1$ expression, but the silencing was apparently incomplete, as low levels of expression were detectable with RT-PCR (Figure 1A). In contrast to cancer cell lines, no methylation of Wnt antagonist genes was detected in normal breast tissue (Figure 1B).

To analyse the methylation status in more detail, we carried out bisulphite sequencing in selected cell lines. Sequencing analysis revealed that the CpG islands of SFRP1, SFRP2 and SFRP5 are extensively methylated in MCF-7 cells (Figure 2A-C). By contrast, almost no methylation of SFRP1 was detected in MDA-MB-436 cells (Figure $2 \mathrm{~A}$ ), which is consistent with the MSP results and the finding that these cells express SFRP1 (Figure 1). We also analysed SFRP2 in MDA-MB-436 cells, where both methylated and unmethylated DNA was detected by MSP. Bisulphite sequencing revealed a heterogeneous pattern of SFRP2 methylation (Figure 2B), and the incomplete silencing of SFRP2 in this cell line likely reflects the low-density methylation of the gene. A
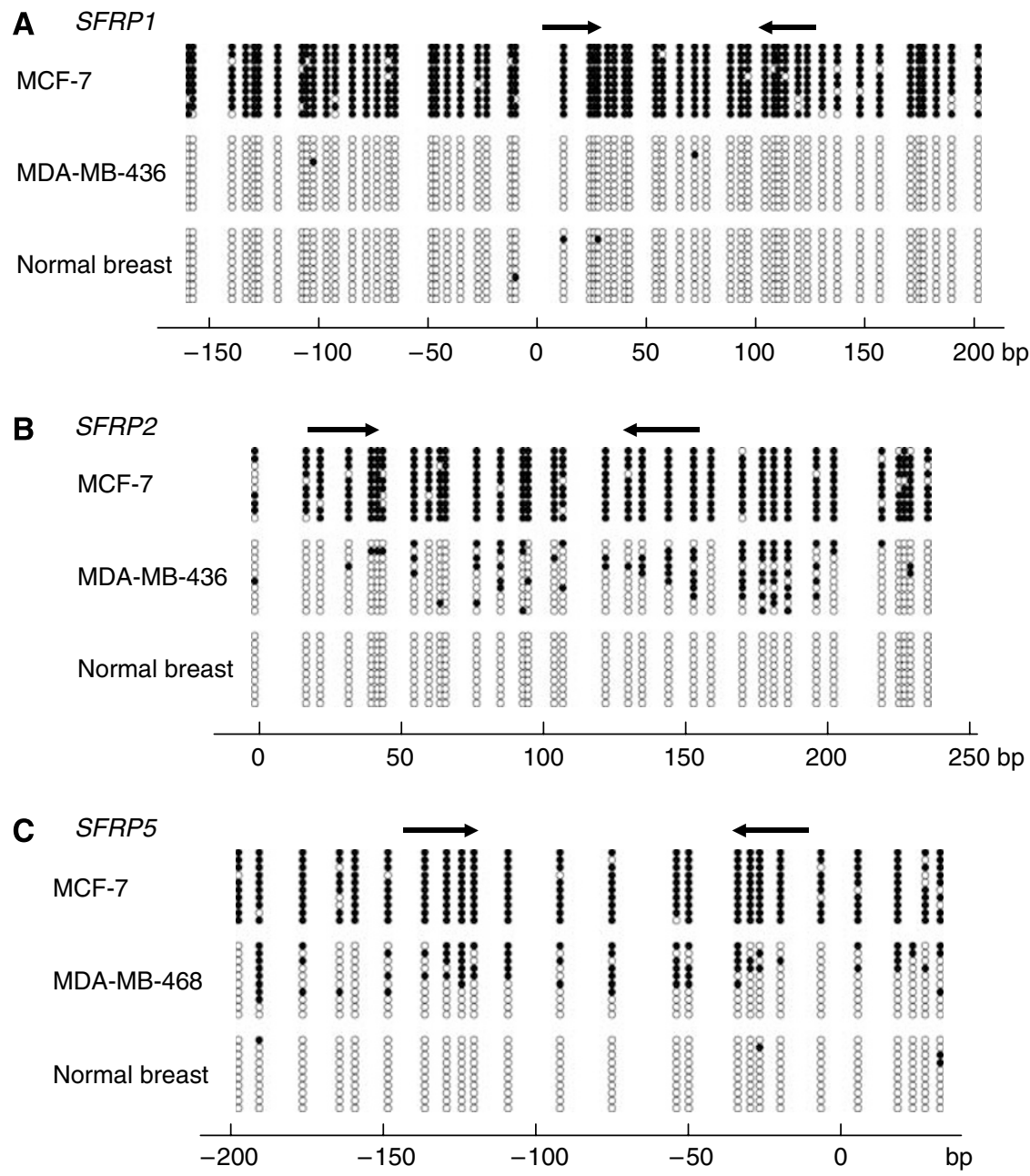

Figure 2 Bisulphite-sequencing analysis of SFRP gene methylation. (A) Bisulphite sequencing of SFRPI in the indicated breast cancer cell lines and normal breast tissue. Open and filled circles represent unmethylated and methylated CpG sites, respectively. The locations of MSP primer sites are shown by arrows on the top. The location of each CPG site relative to the transcription start site is shown below. (B. C) Bisulphite sequencing of SFRP2 (B) and SFRP5 (C). CpG sites are represented as in panel A. 
similar heterogeneous methylation pattern was observed for SFRP5 in MDA-MB-468 cells, where partial methylation was detected with MSP (Figures 1A and 2C). Normal breast tissue showed little or no methylation of SFRP1, SFRP2 or SFRP5 (Figure 2A-C).

\section{Analysis of Wnt antagonist gene methylation in primary breast tumours}

Our finding of epigenetic silencing of SFRP genes and DKK1 in breast cancer cell lines prompted us to determine the extent to which these Wnt antagonist genes are also aberrantly methylated in primary breast tumours. We first analysed SFRP methylation in 38 breast tumour specimens and frequently found SFRP methylation in these tumours (SFRP1, 12 out of $38,32 \%$; SFRP2, 28 out of

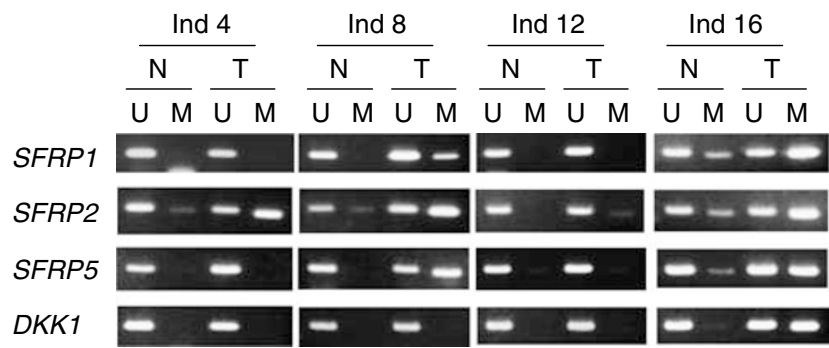

Figure 3 Analysis of methylation of Wnt antagonist genes in primary breast cancers. Shown are representative results of MSP analysis of SFRP I, SFRP2, SFRP5 and DKKI in primary breast cancer tissues ( $T$ ) and adjacent normal breast tissues from the same patients $(\mathrm{N})$.
$38,74 \%$; SFRP5, 22 out of $38,58 \%$ ). We then examined the 78 specimens from Japanese breast cancer patients and found the SFRP genes to be methylated at similar frequencies (SFRP1, 31 out of 78, 40\%; SFRP2, 60 out of 78, 77\%; SFRP5, 55 out of 78,71\%). On the other hand, methylation of DKK1 was detected in only 15 (19\%) of the 78 tumours. We also obtained samples of adjacent non-tumourous breast tissue from 20 of the 78 Japanese patients. In general, methylation of SFRPs and DKK1 was tumour-specific or tumour-predominant, but weak methylation of SFRP genes was observed in some non-tumourous breast tissues (representative results are shown in Figure 3). This may have been caused by field defects.

The clinicopathological features were available from the Japanese patients, but there were no significant correlations between the methylation status of the Wnt antagonist genes and age, pT status, pN status, pM status, oestrogen receptor status or HER2 status (Table 2).

\section{SFRPs suppress breast cancer cell growth}

To determine whether SFRP genes function as tumour suppressors in breast cancer, we next analysed Wnt signalling in breast cancer cells. We first used RT-PCR to test for the expression of Wnt ligands. We found that all of the cell lines expressed at least 6 of the $11 \mathrm{Wnt}$ ligand genes tested (Figure 4). Subsequent immunofluorescence analysis of the intracellular distribution of $\beta$-catenin in seven breast cancer cell lines (MCF-7, MDA-MB-231, MDA-MB435S, MDA-MB-436, MDA-MB-468, T-47D and SK-BR-3) revealed nuclear accumulation of $\beta$-catenin in four cell lines (MCF-7, MDAMB-231, T-47D and SK-BR-3) in which SFRP1, SFRP2 and SFRP5 were silenced (Supplementary Figure 1). No mutation of $A P C$,

Table 2 Clinicopathological features of breast cancer with or without Wnt antagonist genes methylation

\begin{tabular}{|c|c|c|c|c|c|c|c|c|c|c|c|c|c|}
\hline & \multirow[b]{2}{*}{$n$} & \multicolumn{3}{|c|}{ SFRPI } & \multicolumn{3}{|c|}{ SFRP2 } & \multicolumn{3}{|c|}{ SFRP5 } & \multicolumn{3}{|c|}{ DKKI } \\
\hline & & $\mathbf{u}$ & $\mathbf{M}$ & $P$-value & $\mathbf{u}$ & $\mathbf{M}$ & $P$-value & $\mathbf{u}$ & $\mathbf{M}$ & $P$-value & $\mathbf{u}$ & $\mathbf{M}$ & $P$-value \\
\hline Total & 78 & 47 & 31 & & 18 & 60 & & 23 & 55 & & 63 & 15 & \\
\hline Age (years, mean \pm s.d.) & & $53.66 \pm \mid 1.01$ & $52.22 \pm 11.97$ & & $53.56 \pm 12.03$ & $52.95 \pm 11.24$ & & $52.78 \pm 8.88$ & $53.22 \pm 12.31$ & & $52.46 \pm 11.43$ & $55.73 \pm 10.96$ & \\
\hline \multicolumn{14}{|l|}{ pT category } \\
\hline pTis & I & 0 & । & 0.796 & 0 & I & 0.629 & 0 & । & 0.860 & । & 0 & 0.129 \\
\hline PTI & 17 & 12 & 5 & & 4 & 13 & & 6 & 11 & & 13 & 4 & \\
\hline рT2 & 41 & 25 & 16 & & 11 & 30 & & 10 & 31 & & 32 & 9 & \\
\hline PT3 & 8 & 4 & 4 & & 1 & 7 & & 5 & 3 & & 8 & 0 & \\
\hline pT4 & 7 & 5 & 2 & & I & 6 & & I & 6 & & 7 & 0 & \\
\hline \multicolumn{14}{|l|}{ pN category } \\
\hline pNO & 35 & 20 & 15 & 0.809 & 9 & 26 & 0.678 & 7 & 28 & 0.125 & 29 & 6 & 0.747 \\
\hline $\mathrm{pNI}$ & 28 & 20 & 8 & & 6 & 22 & & II & 17 & & 21 & 7 & \\
\hline $\mathrm{pN} 2$ & 6 & 2 & 4 & & 2 & 4 & & I & 5 & & 6 & 0 & \\
\hline pN3 & 3 & 2 & i & & 0 & 3 & & 2 & I & & 3 & 0 & \\
\hline \multicolumn{14}{|l|}{ pM category } \\
\hline pMO & 66 & 40 & 26 & 1.000 & 17 & 49 & 0.325 & 20 & 46 & 0.664 & 53 & 13 & 0.583 \\
\hline pMI & 6 & 4 & 2 & & 0 & 6 & & I & 5 & & 6 & 0 & \\
\hline \multicolumn{14}{|l|}{$E R$} \\
\hline Negative & 15 & 10 & 5 & 0.517 & 6 & 9 & 0.292 & 6 & 9 & 0.128 & 14 & 1 & 0.286 \\
\hline Positive & 26 & 13 & 13 & & 5 & 21 & & 4 & 22 & & 19 & 7 & \\
\hline \multicolumn{14}{|l|}{ HER2 } \\
\hline Negative & 24 & 15 & 9 & 0.353 & 9 & 15 & 0.086 & 5 & 19 & 0.714 & 19 & 5 & 0.714 \\
\hline Positive & 18 & 8 & 10 & & 2 & 16 & & 5 & 13 & & 15 & 3 & \\
\hline \multicolumn{14}{|l|}{ Histology } \\
\hline Ductal carcinoma in situ & 4 & 3 & । & & 2 & 2 & & । & 3 & & 4 & 0 & \\
\hline Invasive ductal carcinoma & 63 & 37 & 26 & & 11 & 52 & & 18 & 45 & & 51 & 12 & \\
\hline Lobular carcinoma in situ & 0 & 0 & 0 & & 0 & 0 & & 0 & 0 & & 0 & 0 & \\
\hline Invasive lobular carcinoma & 2 & । & । & & 0 & 2 & & l & । & & । & । & \\
\hline Others & 7 & 6 & i & & 4 & 3 & & 3 & 4 & & 5 & 2 & \\
\hline
\end{tabular}

$E R=$ oestrogen receptor; HER2 = human epidermal growth factor receptor 2. 


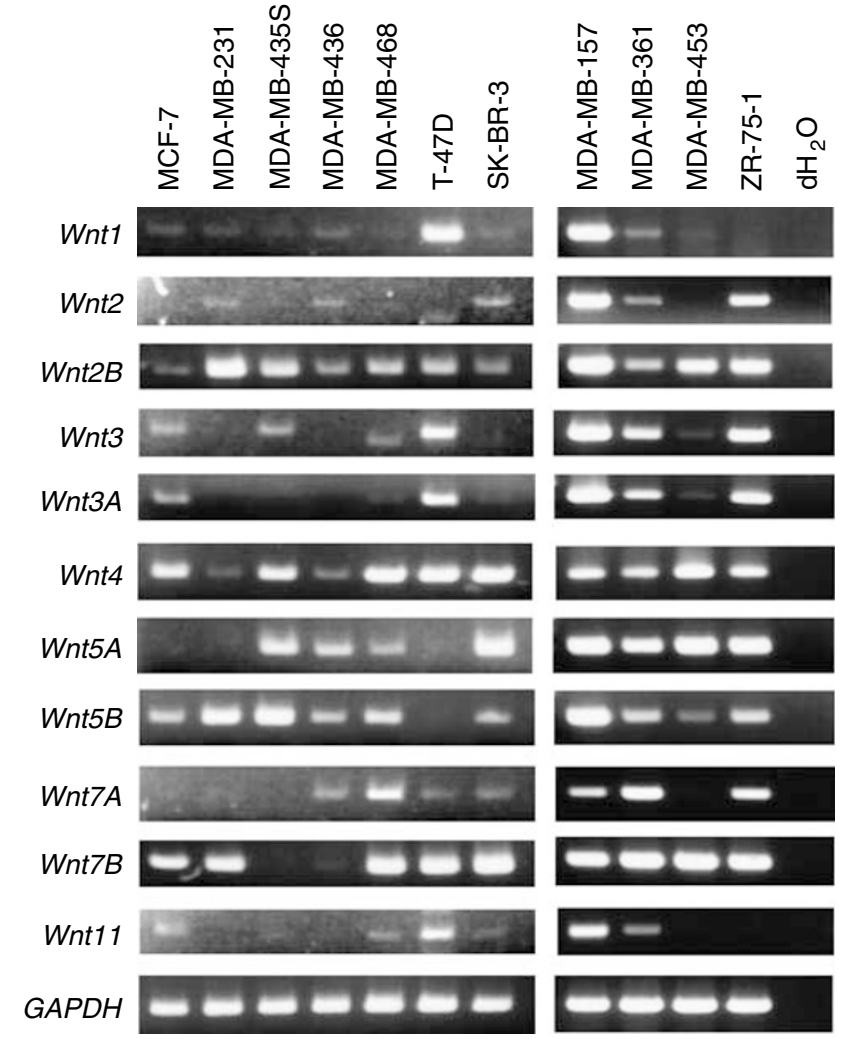

Figure 4 Expression of various Wht ligands in breast cancer cells. Results of RT-PCR analysis of Wnt ligand gene expression in the indicated breast cancer cell lines are shown. GAPDH expression was assessed in all samples to ensure the cDNA quality; $\mathrm{dH}_{2} \mathrm{O}$ indicates no RNA added.

CTNNB1 or AXIN genes has been reported in these cell lines, suggesting that loss of SFRP gene function might be responsible for the observed activation of Wnt signalling. To test that idea, we carried out colony formation assays with MCF-7, T-47D and SKBR-3 cells and found that colony formation was diminished in all cells transfected with any one of the SFRP genes (Figure 5A and B). Subsequent FACS analysis confirmed induction of apoptosis in SKBR-3 cells, showing ectopic expression of SFRPs (Figure 5C).

To test whether the silencing of SFRP expression provides a growth advantage to breast cancer cells, we examined the effect of using siRNA (siSFRP1) to disrupt SFRP1 expression. We initially used three breast cancer cell lines (MDA-MB-435S, MDAMB-436 and MDA-MB-468) to assess the knockdown efficiency of our siSFRP1, which most effectively disrupted SFRP1 expression in MDA-MB-436 cells (Figure 5D). Subsequent MTT assays showed that knocking down SFRP1 expression with siSFRP1 increased cell viability, as compared to cells transfected with control siRNA (Figure 5E). Secreted frizzled-related proteins thus appear to suppress breast cancer cell growth, suggesting that they act as tumour suppressors in breast cancer.

\section{Depletion of SFRP1 upregulates Wnt signalling in breast cancer cells}

To examine the effect of SFRPs on Wnt signalling in breast cancer, we used a TCF/LEF-responsive reporter (pGL3-OT) to analyse the basal TCF/LEF transcriptional activity in seven breast cancer cell lines (MCF-7, MDA-MB-231, MDA-MB-435S, MDA-MB-436, MDA-MB-468, T-47D and SK-BR-3). However, none of the cell lines showed upregulated transcriptional activity (data not shown). We therefore next used siRNA (siSFRP1) to disrupt SFRP1 expression in a breast cancer cell line (MDA-MB-436) and tested whether loss of SFRP function leads to upregulated Wnt signalling. Although transient transfection of siSFRP1 reduced levels of SFRP1 mRNA by approximately $90 \%$ (Figure $6 \mathrm{~A}$ and B), no upregulation in TCF/LEF transcriptional activity was observed (Figure 6C), and expression of TCF/LEF target genes was unchanged (Figure 6A, D and $\mathrm{E})$.

By contrast, transient transfection of a mutant form of $\beta$-catenin $(\beta$-catenin $\Delta 45)$ induced a 10 -fold increase of pGL3-OT reporter activity (Figure 6C) and upregulated the mRNA expression of AXIN2 and MMP7, two TCF/LEF target genes (Figure 6A, D and E). Furthermore, reporter assays and analysis of target gene expression revealed that the combination of SFRP1 depletion and $\beta$-catenin $\Delta 45$ overexpression acted synergistically to upregulate TCF/LEF transcription (Figure 6A, C-E).

\section{DISCUSSION}

Compelling evidence suggests that activation of Wnt signalling plays an important role in breast cancer. Immunohistochemical staining carried out by several groups has demonstrated elevated levels of nuclear and/or cytoplasmic $\beta$-catenin in breast tumours with significant frequency (Lin et al, 2000; Ryo et al, 2001; Chung et al, 2004). Lin et al (2000) also showed that nuclear and/or cytoplasmic staining of $\beta$-catenin correlated with elevated cyclin D1, which is one of the known targets of $\beta$-catenin/TCF transcription. However, mutation of APC, CTNNB1 or AXIN is rare in breast cancer, and thus the mechanism of Wnt signal activation in this disease is not fully understood.

On the basis of their expression array analysis of chromosome 8p11-21 genes, Ugolini et al (1999) reported that expression of SFRP1 mRNA is frequently diminished or lost in breast carcinomas, and they also found that loss of SFRP1 occurs in more than $80 \%$ of invasive breast carcinomas, although not in the medullary type (Ugolini et al, 2001). Using immunohistochemical analysis, Klopocki et al (2004) found that expression of SFRP1 protein was absent in $46 \%$ of invasive breast tumours and in $43 \%$ of carcinoma in situ. In addition, two groups recently reported frequent SFRP1 methylation in primary breast tumours (Lo et al, 2006; Veeck et al, 2006), and Bafico et al (2004) clearly demonstrated a novel autocrine mechanism leading to constitutive Wnt signalling in breast cancer, which could be suppressed by SFRP1 and DKK1. Taken together, these results suggest that loss of SFRP1 function is a key mechanism by which Wnt signalling is activated in breast cancer.

To date, four SFRP family genes (SFRP1, SFRP2, SFRP4 and $S F R P 5)$ and two DKK family genes (DKK1 and DKK3) have been identified as targets of epigenetic silencing in human tumours (Suzuki et al, 2002; Roman-Gomez et al, 2004; Lodygin et al, 2005; Aguilera et al, 2006; Niehrs, 2006). Among them, we showed that loss of SFRP1, SFRP2 and SFRP5 contributes to Wnt signal activation in both CRC and GC. Dickkopf proteins bind with LRP5/ 6 and inhibit Wnt signalling by preventing Wnt and $\mathrm{Fz}$ from forming a ternary complex with LRP5/6. However, among the DKK family, DKK3 is the most divergent, as it neither binds LRP5/6 nor significantly affects Wnt singling (Niehrs, 2006). We therefore analysed methylation and expression status of SFRP1, SFRP2, SFRP5 and DKK1. SFRP1, SFRP2, SFRP5 and DKK1 were methylated in $64,100,91$ and $27 \%$ of the breast cancer cell lines tested, respectively. In primary breast tumours, methylation frequencies of SFRP1, SFRP2, SFRP5 and DKK1 were 40, 77, 71 and $19 \%$, respectively. Although the frequency of SFRP1 methylation in our samples was somewhat lower than those reported by Lo et al (2006) and Veeck et al (2006), we also found that a substantial number of breast tumours harbour SFRP1 methylation. In addition, we found that SFRP2 and SFRP5 are methylated in both cultured breast cancer cells and primary breast cancers at quite high frequencies. In contrast to SFRP genes, however, the frequency of $D K K 1$ methylation in breast cancer was relatively limited. 

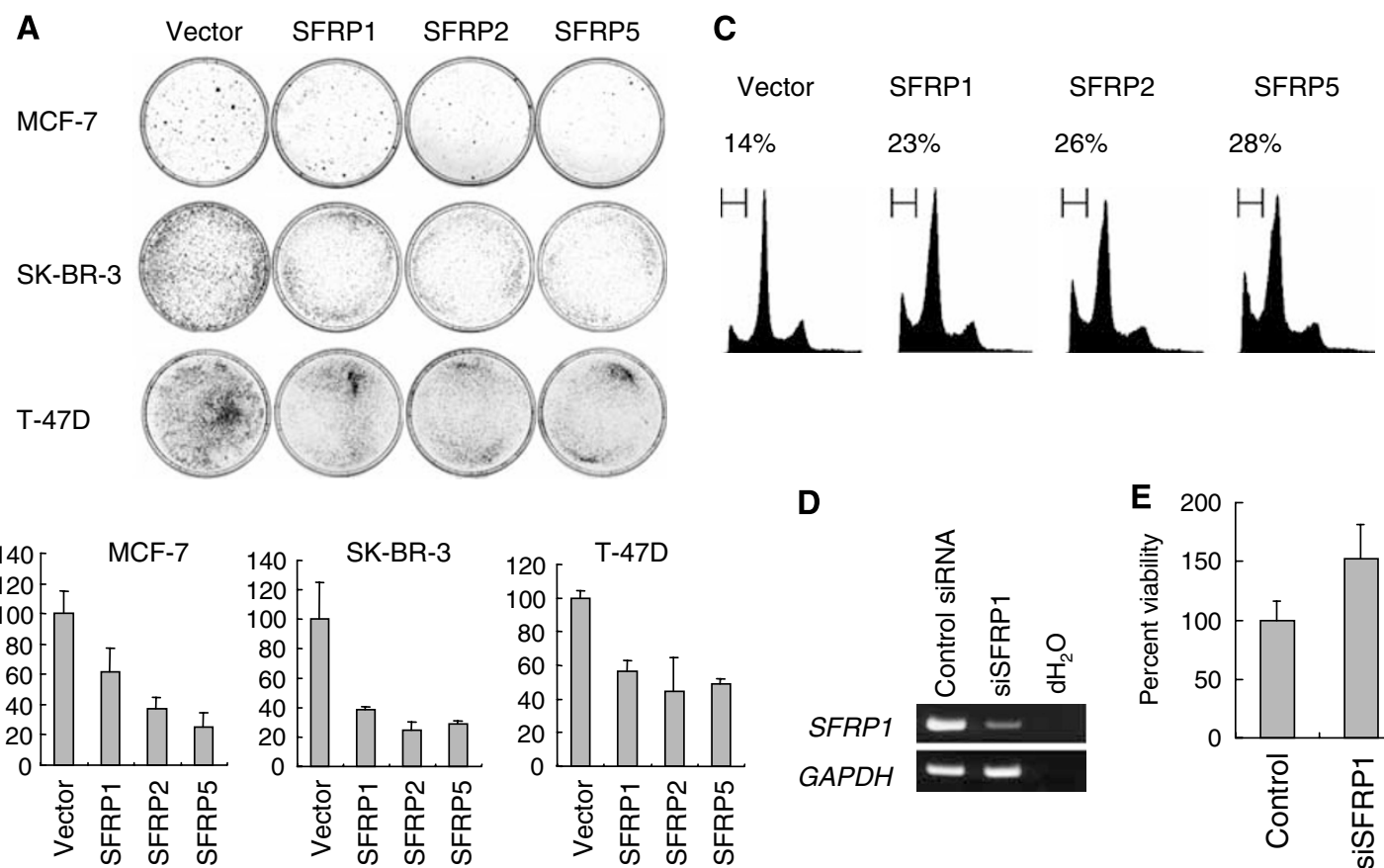

Figure 5 SFRPs suppress breast cancer cell proliferation. (A) Representative results from a colony formation assay carried out using the indicated breast cancer cell lines transfected with SFRP or control plasmid (vector). (B) Relative colony formation efficiencies of breast cancer cells transfected with SFRP or control plasmid (vector). Shown are means of three replications; error bars represent standard deviations. (C) Representative results of a FACS analysis of SK-BR-3 cells transfected with SFRP or control plasmid (vector). Cells were harvested and analysed $48 \mathrm{~h}$ after transfection. Apoptotic cells appear as the subGI fraction, and percentages are shown on the top. (D) RT-PCR analysis of SFRPI expression in MDA-MB-436 cells transfected with control siRNA or siSFRPI. GAPDH expression was assessed in all samples to ensure the quality of the cDNA; $\mathrm{dH}_{2} \mathrm{O}$ indicates no RNA added. (E) Depletion of SFRPI upregulated proliferation of breast cancer cells. MDA-MB-436 cells were transfected with control siRNA or siSFRPI, and cell viabilities were determined in MTT assays carried out $48 \mathrm{~h}$ after transfection. Values were normalised relative to cells transfected with control siRNA. Shown are means of eight replications; error bars represent standard deviations.

To examine the activity of Wnt signalling in breast cancer, we evaluated the expression status of the Wnt ligands in the cell lines. We previously found that at least 3 of the $11 \mathrm{Wnt}$ ligands were expressed CRC cell lines (Suzuki et al, 2004), and even more Wnt ligands were expressed in breast cancer cell lines. Using immunofluorescence analysis, we observed $\beta$-catenin to be present in the nuclei of four of seven breast cell lines in which multiple SFRP genes were methylated and silenced. Ectopic expression of SFRP in breast cancer cells suppressed colony formation and induced apoptosis. Conversely, SFRP1 knockdown enhanced breast cancer cell growth. Thus, loss of Wnt antagonists, particularly SFRPs, appears to contribute to Wnt signal activation in breast cancer.

On the other hand, we found that none of the breast cancer cell lines tested showed upregulated TCF/LEF transcriptional activity, even when they showed a loss of Wnt antagonist genes and nuclear accumulation of $\beta$-catenin, which is consistent with our earlier findings in GC cells. Although it is well known that mutation in $A P C, C T N N B 1$ and $A X I N$ is infrequent in GC, we found that the majority of GC cells showed activation and nuclear accumulation of $\beta$-catenin and methylation of multiple SFRP genes (Nojima et al, 2007). Among those GC cells, only a few cell lines in which APC or CTNNB1 was mutated showed significant upregulation of TCF/LEF transcriptional activity (Nojima et al, 2007). It is thus possible that the TCF/LEF reporter assay used may not be sufficiently sensitive to detect the weak or moderate activation of canonical Wnt signalling.

Alternatively, the tumour-suppressive function of Wnt antagonists may be independent of the Wnt/ $\beta$-catenin pathway. To clarify the functional role of SFRP inactivation in breast cancer, we used siRNA to disrupt endogenous SFRP1 expression. Because none of the breast cancer cell lines presented aberrant TCF/LEF transcrip- tion, we used an expression vector encoding a $\beta$-catenin mutant to boost Wnt signalling. We found that the TCF/LEF transcriptional activity induced by the mutant $\beta$-catenin was synergistically upregulated when combined with SFRP1 depletion, which is consistent with the recent observation by Fukui et al (2005). Using non-small-cell lung carcinoma cells in which SFRP1 was methylated, they showed that when SFRP1 was cotransfected with mutant $\beta$-catenin, SFRP1 could attenuate TCF/LEF activity induced by exogenous $\beta$-catenin. Our results demonstrate the potential of endogenous SFRP1 to inhibit the Wnt $/ \beta$-catenin pathway in breast cancer cells.

In summary, we have shown that epigenetic silencing of multiple Wnt antagonist genes is a common event in breast cancer. In particular, we found that SFRP2 and SFRP5 are methylated at even higher frequencies than SFRP1. Taken together, our findings indicate that the majority of breast tumours harbour methylation of at least one Wnt antagonist gene, and support the hypothesis that epigenetic silencing of Wnt antagonist genes is a major cause of constitutive Wnt signalling in breast cancer. Our data also suggest that methylation of a set of multiple Wnt antagonist genes may represent a useful marker in breast cancer.

\section{ACKNOWLEDGEMENTS}

We thank Dr William Goldman for editing this manuscript. This study was supported in part by Grants-in-Aid for Scientific Research on Priority Areas from the Ministry of Education, Culture, Sports, Science and Technology (MT, KI and TT), Grantsin-Aid for Scientific Research (S) from Japan Society for Promotion of Science (KI), Grant-in-Aid for the Third-term 
A

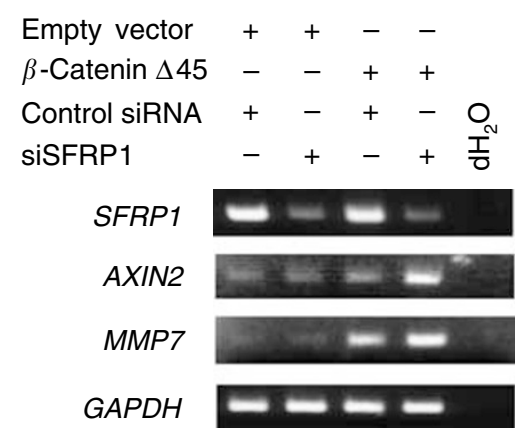

D

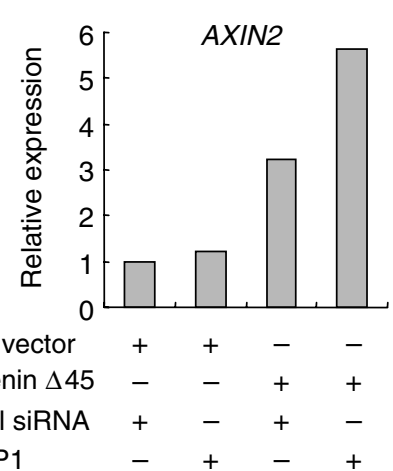

B
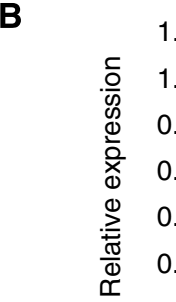
$\beta$-Catenin $\Delta 4$ Control siRNA siSFRP1
Empty vecto

SFRP1

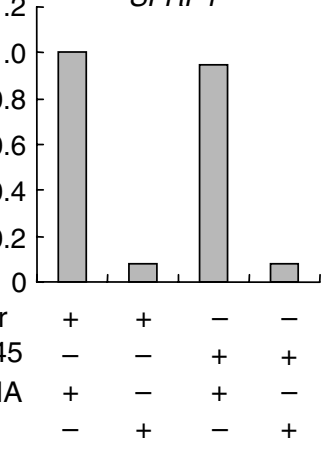

E

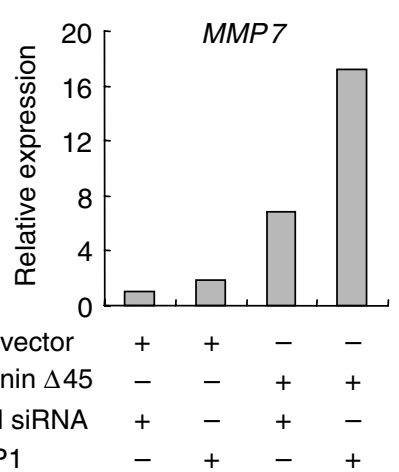

C

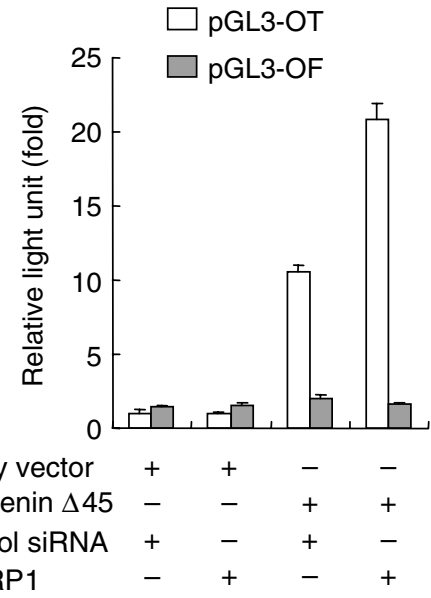

Figure 6 Depletion of SFRPI upregulates Wnt signalling in breast cancer cells. (A) RT-PCR analysis of SFRPI and Wnt target genes in MDA-MB-436 cells cotransfected with $\beta$-catenin $\Delta 45$ or an empty vector plus control siRNA or siSFRPI. GAPDH expression was assessed in all samples to ensure the cDNA quality; $\mathrm{dH}_{2} \mathrm{O}$ indicates no RNA added. (B) Real-time RT-PCR analysis of SFRPI in MDA-MB-436 cells cotransfected with $\beta$-catenin $\Delta 45$ or an empty vector plus control siRNA or siSFRPI. Results are normalised to endogenous GAPDH expression. (C) Relative luciferase activity obtained using a TCF/LEFresponsive reporter ( $\mathrm{pGL3}-\mathrm{OT}$ ) or a negative control (pGL3-OF) in MDA-MB-436 cells cotransfected with $\beta$-catenin $\Delta 45$ or an empty vector plus control siRNA or siSFRPI. Results are shown relative to a value of I (assigned to cells transfected with empty vector and control siRNA) after correction for transfection efficiency using Renilla luciferase activity. Shown are means of four replications; error bars represent standard deviations. (D, E) Real-time RTPCR analysis of AXIN2 (D) and MMP7 (E) in MDA-MB-436 cells cotransfected with $\beta$-catenin $\Delta 45$ or an empty vector plus control siRNA or siSFRPI. Results are normalised to endogenous GAPDH expression.

Cancer Control Strategy and Grant-in-Aid for Cancer Research from the Ministry of Health, Labor, and Welfare, Japan (MT).

\section{REFERENCES}

Aguilera O, Fraga MF, Ballestar E, Paz MF, Herranz M, Espada J, Garcia JM, Munoz A, Esteller M, Gonzalez-Sancho JM (2006) Epigenetic inactivation of the Wnt antagonist Dickkopf-1 (DKK-1) gene in human colorectal cancer. Oncogene 25: 4116-4121

Armes JE, Hammet F, de Silva M, Ciciulla J, Ramus SJ, Soo WK, Mahoney A, Yarovaya N, Henderson MA, Gish K, Hutchins AM, Price GR, Venter DJ (2004) Candidate tumor-suppressor genes on chromosome arm $8 \mathrm{p}$ in early-onset and high-grade breast cancers. Oncogene 23: 5697-5702

Bafico A, Liu G, Goldin L, Harris V, Aaronson SA (2004) An autocrine mechanism for constitutive Wnt pathway activation in human cancer cells. Cancer Cell 6: 497-506

Bui TD, Rankin J, Smith K, Huguet EL, Ruben S, Strachan T, Harris AL, Lindsay S (1997) A novel human Wnt gene, WNT10B, maps to $12 \mathrm{q} 13$ and is expressed in human breast carcinomas. Oncogene 14: 1249-1253

Cadigan KM, Nusse R (1997) Wnt signaling: a common theme in animal development. Genes Dev 11: 3286-3305

Chung GG, Zerkowski MP, Ocal IT, Dolled-Filhart M, Kang JY, Psyrri A, Camp RL, Rimm DL (2004) Beta-catenin and p53 analyses of a breast carcinoma tissue microarray. Cancer 100: 2084-2092

Dale TC, Weber-Hall SJ, Smith K, Huguet EL, Jayatilake H, Gusterson BA, Shuttleworth G, O'Hare M, Harris AL (1996) Compartment switching of WNT-2 expression in human breast tumors. Cancer Res 56: $4320-4323$
Supplementary Information accompanies the paper on British Journal of Cancer website (http://www.nature.com/bjc)
Fukui T, Kondo M, Ito G, Maeda O, Sato N, Yoshioka H, Yokoi K, Ueda Y, Shimokata K, Sekido Y (2005) Transcriptional silencing of secreted frizzled related protein 1 (SFRP 1) by promoter hypermethylation in non-small-cell lung cancer. Oncogene 24: 6323-6327

Huguet EL, McMahon JA, McMahon AP, Bicknell R, Harris AL (1994) Differential expression of human Wnt genes 2, 3, 4, and 7B in human breast cell lines and normal and disease states of human breast tissue. Cancer Res 54: 2615-2621

Jones SE, Jomary C (2002) Secreted frizzled-related proteins: searching for relationships and patterns. BioEssays 24: 811-882

Kawano Y, Kypta R (2003) Secreted antagonists of the Wnt signalling pathway. J Cell Sci 116: 2627-2634

Klopocki E, Kristiansen G, Wild PJ, Klaman I, Castanos-Velez E, Singer G, Stohr R, Simon R, Sauter G, Leibiger H, Essers L, Weber B, Hermann K, Rosenthal A, Hartmann A, Dahl E (2004) Loss of SFRP1 is associated with breast cancer progression and poor prognosis in early stage tumors. Int J Oncol 25: 641-649

Lin SY, Xia W, Wang JC, Kwong KY, Spohn B, Wen Y, Pestell RG, Hung MC (2000) Beta-catenin, a novel prognostic marker for breast cancer: its roles in cyclin D1 expression and cancer progression. Proc Natl Acad Sci USA 97: $4262-4266$

Lo PK, Mehrotra J, D’Costa A, Fackler MJ, Garrett-Mayer E, Argani P, Sukumar S (2006) Epigenetic suppression of secreted frizzled related 
protein 1 (SFRP1) expression in human breast cancer. Cancer Biol Ther 5: $281-286$

Lodygin D, Epanchintsev A, Menssen A, Diebold J, Hermeking H (2005) Functional epigenomics identifies genes frequently silenced in prostate cancer. Cancer Res 65: 4218-4227

Niehrs C (2006) Function and biological roles of the Dickkopf family of Wnt modulators. Oncogene 25: 7469-7481

Nojima M, Suzuki H, Toyota M, Watanabe Y, Maruyama R, Sasaki S, Sasaki Y, Mita H, Nishikawa N, Yamaguchi K, Hirata K, Itoh F, Tokino T, Mori M, Imai K, Shinomura Y (2007) Frequent epigenetic inactivation of SFRP genes and constitutive activation of Wnt signaling in gastric cancer. Oncogene 26: 4699-4713

Polakis P (2000) Wnt signaling and cancer. Genes Dev 14: $1837-1851$

Roman-Gomez J, Jimenez-Velasco A, Agirre X, Castillejo JA, Navarro G, Barrios M, Andreu EJ, Prosper F, Heiniger A, Torres A (2004) Transcriptional silencing of the Dickkopfs-3 (Dkk-3) gene by CpG hypermethylation in acute lymphoblastic leukaemia. Br J Cancer 91: 707-713

Ryo A, Nakamura M, Wulf G, Liou YC, Lu KP (2001) Pin1 regulates turnover and subcellular localization of beta-catenin by inhibiting its interaction with APC. Nat Cell Biol 3: 793-801

Stoehr R, Wissmann C, Suzuki H, Knuechel R, Krieg RC, Klopocki E, Dahl E, Wild P, Blaszyk H, Sauter G, Simon R, Schmitt R, Zaak D, Hofstaedter F, Rosenthal A, Baylin SB, Pilarsky C, Hartmann A (2004) Deletions of chromosome $8 \mathrm{p}$ and loss of sFRP1 expression are progression markers of papillary bladder cancer. Lab Invest 84: $465-478$

Suzuki H, Gabrielson E, Chen W, Anbazhagan R, van Engeland M, Weijenberg MP, Herman JG, Baylin SB (2002) A genomic screen for genes upregulated by demethylation and histone deacetylase inhibition in human colorectal cancer. Nat Genet 31: $141-149$

Suzuki H, Watkins DN, Jair KW, Schuebel KE, Markowitz SD, Chen WD, Pretlow TP, Yang B, Akiyama Y, Van Engeland M, Toyota M, Tokino T, Hinoda Y, Imai K, Herman JG, Baylin SB (2004) Epigenetic inactivation of SFRP genes allows constitutive WNT signaling in colorectal cancer. Nat Genet 36: $417-422$

Ting AH, McGarvey KM, Baylin SB (2006) The cancer epigenome components and functional correlates. Genes Dev 20: $3215-3231$

Toyota M, Sasaki Y, Satoh A, Ogi K, Kikuchi T, Suzuki H, Mita H, Tanaka N, Itoh F, Issa JP, Jair KW, Schuebel KE, Imai K, Tokino T (2003) Epigenetic inactivation of CHFR in human tumors. Proc Natl Acad Sci USA 100: $7818-7823$

Ugolini F, Adelaide J, Charafe-Jauffret E, Nguyen C, Jacquemier J, Jordan B, Birnbaum D, Pebusque MJ (1999) Differential expression assay of chromosome arm $8 \mathrm{p}$ genes identifies frizzled-related (FRP1/FRZB) and fibroblast growth factor receptor 1 (FGFR1) as candidate breast cancer genes. Oncogene 18: $1903-1910$

Ugolini F, Charafe-Jauffret E, Bardou VJ, Geneix J, Adelaide J, LabatMoleur F, Penault-Llorca F, Longy M, Jacquemier J, Birnbaum D, Pebusque MJ (2001) WNT pathway and mammary carcinogenesis: loss of expression of candidate tumor suppressor gene SFRP1 in most invasive carcinomas except of the medullary type. Oncogene 20: 5810-5817

Veeck J, Niederacher D, An H, Klopocki E, Wiesmann F, Betz B, Galm O, Camara O, Durst M, Kristiansen G, Huszka C, Knuchel R, Dahl E (2006) Aberrant methylation of the Wnt antagonist SFRP1 in breast cancer is associated with unfavourable prognosis. Oncogene 25: 3479-3488 